\title{
El Egoísmo, la Frustración y el Castigo de la Mujer Mexicana en los Dramas de González Caballero
}

\begin{abstract}
A NTONIO González Caballero, joven dramaturgo mexicano, ha ingresado de modo definitivo en el teatro hispanoamericano al ganar el premio "Juan Ruiz de Alarcón", por su drama El medio pelo, la mejor obra producida en México durante el año de $1964 . *$ El caso de este autor es singular, ya que el referido drama y otro suyo, Una pura..., y dor con sal se sostuvieron en la cartelera simultáneamente. Ambos fueron aclamados como lo mejor que se ha presentado de autor mexicano en más de una década. Hasta ahora, sólo se conoce a González Caballero a través de su más reciente etapa costumbrista, en la que revela una obsesión - consciente o no- por el egoísmo de la naturaleza femenina. Una consideración de sus últimas cuatro obras, que ventilan los problemas de mujeres mexicanas en circunstancias muy diferentes, verifica esta temática. Como censor de la mujer, el autor demuestra cómo, por determinados defectos, ella frustra su felicidad y, a la postre, se inflige su merecido castigo.

Pero antes, para situar al dramaturgo dentro del cuadro literario de su época, conviene señalar brevemente las principales tendencias que se aprecian actualmente en el teatro mexicano, es decir, en el teatro escrito por mexicanos, a diferencia de las obras importadas del extranjero a la capital azteca.1 Al lado del realismo costumbrista, con su preocupación

* Este estudio crítico fue presentado por la autora en la Segunda Sesión del LXIII Congreso del Pbilological Association of the Pacific Coast, que se verificó en la Universidad de California, en Los Angeles, los días 26 y 27 de noviembre de 1965.

1 Estados Unidos, Europa y Asia son representados en las tablas mexicanıs, siendo las obras españolas, francesas, inglesas y alemañas las más conocidas.
\end{abstract}


por problemas de la actualidad hispanoamericana, ${ }^{2}$ hay marcado interés en temas basados en la historia de México, antes y después de la Conquista, incluyendo obras anti-históricas, como las llama Rodolfo Usigli cuando, al valerse de personajes históricos, se permite cierta licencia artística para desarrollar el conflicto. ${ }^{3}$ Redondean el panorama teatral las obras que abarcan conceptos universales y de orden psicológico. Representan aquellos conflictos que podrían ubicarse en cualquier país occidental, razón por la que son preferidos por los autores mexicanos de origen extranjero - en su mayoría españoles nacionalizados-, quienes abiertamente confiesan su incapacidad de pulsar las vibraciones íntimas del nuevo mundo hispánico.4

Al margen de estas tres corrientes convencionales, ha tomado raíz en el campo de la literatura dramática el teatro de vanguardia, que, a partir de Pirandello, viene renovando el género con recursos poéticos, expresionistas, surrealistas y con técnicas heredadas de la modalidad épica de Brecht. Con todo, el hecho de que una obra de índole costumbrista haya ganado el premio del año por encima de excelentes piezas vanguardistas, ${ }^{5}$ comprueba, además del mérito de la obra de González Caballero, que el público y la crítica teatral de México siguen siendo esencialmente conservadores, por predilección, y no por desconocedores, puesto que en los numerosos teatros capitalinos suelen escenificarse no sólo las obras clásicas del mundo entero, sino lo más novedoso de la dramaturgia contempotánea universal. Es de recordarse que, en toda Hispancamérica, México sólo queda a la zaga de Argentina, por lo que toca al género dramático y al número de teatros.

2 Relevantes autores costumbristas del teatro contemporáneo son: Celestino Gorostiza ( $E l$ color de muestra piel), Luisa Josefina Hernández (Los frutos caídos), Emilio Carballido (Rosalba y los Llaveros y Felicidad), Sergio Magaña (Los sig'nos del Zodiaco), Robles Arena (Los desarraigados) y Sánchez Mayans (Las alas del pez).

3 El pasado histórico ha inspirado a casi todos los dramaturgos mexicanos. Un episodio precortesiano fue recreado por Salvader Novo en su última obra, La guerra de las gondas (Ptemio "Juan Ruiz de Alarcón" 1963). Temas de la conquista han sido desarrollados por Sergio Magaña (Mactezuma II), Raúl Moncada (El sitio de Temocbtitlán), S. Novo (Cuaubtémoc), C. Gorostiza ( La Mainche), etc. Han ubicado sus anécdotas dentro de la época virreinal Agustín Lazo (El caso de Don Juan Manuel), Wilberto Cantón (Escuela de cortesanos), y Emilio Carballido (El relojero de Córdoba). El período de la Independencia fue dramatizado por F. S. Inclán en Hidalgo. Wilberto Cantón ganó el premio "Juan Ruiz de Alarcón" 1962 con una obra ambientada en la Revolución mexicana (Nosotros somos Dios); también en esta época se inspiró Usigli para esrribit su obra maestra (El gesticulador).

"Véase: Alyce de Kuehne, "Dramaturgos mexicanos de origen extranjero", Teatro contemporáneo mexicano 1940-1962 (México, 1962), pp. 137-143.

5 Olimpira de Héctor Azar; El señor perro y El bombre y su máscara, ambas de Margarita Urueta. 
La incursión de González Caballero en el arte dramático data de I958, cuando empezó a documentarse sobre los aztecas, para su trilogía indígena. Su producción consta a la fecha de nueve obras de estilo y tema diversos. Tuvo su primer estreno en 1961, con Señoritas a disgusto, la que apunta más su facilidad dramática que su preferencia temática. No of rece ninguna novedad dentro de aquella vena costumbrista prácticamente agotada por Luisa Josefina Hernández en sus obras iniciales (Aguardiente de 'caña y Los sordomusdos), así como por Emilio Carballido, en La danza que sueña la torhugat Todas estas obras coinciden en presentar a dos hermanas solteronas de provincia. Los casos de frustración femenina planteados por Luisa Jocefina Hernández adolecen de una atmósfera en exceso deprimente y recargada de amargura, ya que el par de hermanas en ambas obras achacan su desdicha a un hermano suyo - en una obra, por disoluto, y en la otra, por demente. En cambio, Carballido y González Caballero han sabido pintar a las hermanas solteras con tonos subidos y tonos sombríos, con humorismo y patetismo, y con todos los matices que exige la anormalidad de estos personajes, cuyo destino biológico se ha truncado.

Señoritals a disgusto trata de unas "niñas" cuarentonas, huerfanitas todavía al cuidado de su niñera, como ccurre a menudo en la proxincia mexicana. Es el consabido caso de las hermanas que se acompañan en el otoño de su vida, tras haber dejado pasar la primavera, debido a sus propias exigencias o prejuicios. Sus vidas incoloras cambian repentinamente el día que alquilan un cuarto a un joven que llega de la capital. Cómo el pavor de tener en casa a un "hombre" se convierte paulatinamente en una satisfacción de sentirse protegidas por él, y cómo, por fin, las dos hermanas llegan a rivalizar en su amor tan ingenuo y patético hacia el huésped - como si fueran niñas de verdad - todo esto constituye el nudo flojo de esta anécdota que, sin embargo, conmueve por las pinceladas de tragicomedia.

Cabe señalar que trátase de un dramaturgo que es, en efecto, pintor; así se dio a conocer primero en el mundo artístico. Sucede que en un momento dado la pintura ya no le satisfizo, por carecer de la tercera dimensión sicológica que a él le hacía falta para expresarse cabalmente. Además, siempre le ha causado infinita tristeza el separarse de sus cuadros a la hora de venderlos. En cambio, el caso de una obra teatral es todo lo contrario; lejos de perder contacto con ella, la aprecia cada vez mejor, retocada y perfeccionada por el director y los actores que intervienen en su realización. Gonzálcz Caballero jamás se opone a modificaciones dialogísticas, siempre que estén de acuerdo con el estudio in- 
terior del personaje y su correspondencia con el medio exterior. Ello explica la entereza de sus caracterizaciones y la fluidez de los parlamentos, genuinamente salpicados de modismos y palabras de raíces indolatinas muy peculiares de la República Mexicana.

A su pieza Rosa sabe una cosa, al estrenarla en I964, le cambiaron el título a Una pura. . . y dos con sal, expresión de auténtica vulgaridad que anuncia el clima de la vecindad de una colonia indigente del Distrito Federal, donde transcurre la acción. ${ }^{6}$ No es de extrañarse que el ambiente recuerde Los signos del Zodíaco de Sergio Magaña; todas las vecindades tienen rasgos comunes. Pero sí causa admiración el que González CabaIlero haya logrado el mismo ambiente, no con 30 ó 40 personajes, sino con sicte, todos hábilmente entrelazados los unos con los otros, de modo que no puedan escaparse del destino que tejen la maldad y la envidia. Si Los s'gnos del Zodíaco denuncia la consabida iniquidad social derivada de la injusta distribución de 'los bienes, la obra de González Caballero se concentra en la injusticia que cometen unos contra otros dentro del mismo estrato social. Como ha observado el autor, mientras que la civilización atómica amenaza con la destrucción global, los seres humanos se destruyen a sí mismos dentro de sus pequeños mundos miserables.

Con su frustración sexua'l, Rosa, la portera, es la que siembra la tragedia entre los vecindarios. A diferencia de las castas señoritas, "a disgusto" por su soltería, a Rosa le inquieta una enorme preocupación sexual que la emparienta con las malas mujeres de las obras de Tennessee Williams. Margo Glantz, catedrática y crítica teatral, la llamaría "endemoniada", término que ella aplica a las víctimas del sexo que tanto se repiten en la temática del dramaturgo norteamericano. ${ }^{7}$ Rosa persigue a un boxeador, que viene a ser el prototipo de la virilidad, pero ni con dinero logra seducirlo. El, por su parte, se ha prendado de Lupita, joven vecina que ni siquiera sospecha la pasión que ha desatado. Rosa procede a vencer a la que considera su rival, por lo que lanza el chisme de que Lupita es amante de un casado; nada menos que el señor más serio y cumplido de la vecindad: Felipe, quien vive y trabaja sólo por Aurora y su pequeño hijo. Rosa, la portera, barrerá de paso con la felicidad de este joven matrimonio.

Lo magistral de la obra estriba en el proceso sicológico que se des-

6 "Una pura... y dos con sal" es una expresión que tiene su origen en dos bebidas alcohólicas que, por su ecanómica fermentación se han hecho demasiado accesibles a la plebe. "Una pura" alude a la copa del tequila, que puede tomarse en su estado puro, es decir, solo. "Dos con sal" se refiere al mezcal que, por su inferioridad, necesita condimentarse con sal.

7 Margo Glantz, Tennessee Williams y el teatro norteamericano. Texto del Teatro de la Univerșidad de México número 11 (México, 1964). 
envuelve a raíz de aquella mentira, tomada primero con una sonrisa incrédula por Aurora, pero que va encendiendo su imaginación y creciendo como un monstruo que acaba llenando por completo el pequeño hogar, hasta que Aurora ya no cabe allí. Se refugia en la casa de sus padres, a pesar de que Felipe le ruega volver con él. Viene la degeneración de Felipe, que abandona el trabajo para ahogarse en el alcohol. Así lo encuentra Aurora, cuando por fin regresa arrepentida. Entonces le toca a Felipe rechazarla a ella, provocándola además con comentarios referentes a su supuesta "amante". Aurora le hunde un cuchillo en eil vientre, pero al momento expía su pecado al enterarse de que lo ha asesinado por un chisme que fue, en efecto, una mentira. Aurora sufre, por eso, un doble castigo, siendo quizás el desprecio de Felipe el más cruel, el que la orilla a la locura y al crimen. Parecerá una pena excesiva para una mujer que ha sido víctima de un engaño. Pero aún suponiendo que Felipe le hubiera sido infiel, ¿por qué no tuvo la nobleza de perdonarlo? Concedido es que la trastornan los celos, pero esta pasión no puede perdonársele, como tampoco se perdona el crimen de Otelo cuando estrangula a Desdémona.

Al mismo tiempo de ponerse esta obra de tema urbano, otra empresa representaba la que había de ganar el premio del año, El medio pelo, ambientada en provincia, concretamente en el Estado de Guanajuato, donde nació su autor. ${ }^{8}$ Este drama, menos fogoso que el anterior, está igualmente penetrado de un espíritu hispanoamericano, en este caso orientado hacia la soberbia de ciertas familias seudoaristocráticas, cuya arrogancia desciende en línea directa de los conquistadores, por su desprecio al trabajo manual como ocupación deshonrosa. Por complejos de esta naturaleza, doña Paz García viuda de Pérez desdeña la proposición de matrimonio de don Lupe, un próspero agricultor que, no obstante, se empeña en llevar como singular objeto de vestir el jorongo indígena - una tela tosca rectangular, con una abertura en el centro para la cabeza-, que viene siendo el símbolo de su sana sencillez y su humildad ranchera. Pero doña Paz juzga a los seres humanos de modo arbitrario, según sus raíces sociales: la pelusa es la chusma que no cuenta; el medio pela es el elemento intermedio, burdo como don Lupe, y ella, en una categoría superior, es una dama de terciopelo.

- Una pura... y dos con sal fue estrenada el 14 de agosto de 1964, en el Teatro Rotonda. El medio pelo fue estrenada el 27 de agosto de 1964, en el Teatro Urueta. Ambas abras se repusieron en abril de 1965 , El medio pelo en el Teatro Virginia Fábregas, en una Temporada de la Unión Nacional de Autores Mexicanos. Esta última obra se edita, junto con otras obras mexicanas, pof Aguilar, en un volumęn țitulado Teatro Mexicano 1964. 
Lupe, en cambio, no confía en su criterio personal para juzgar a las personas y mucho menos para escoger a una esposa. A raíz de esto el dramaturgo introduce, como subtema, la prevalencia de las supersticiones derivadas de las circunstancias en que nace uno, es decir, en su horóscopo. Cuando don Lupe desea cerciorarse si será o no compatible con la viuda (en sus amoríos anteriores le había motivado sólo el instinto bruto), recurre a la llamada ciencia adivinatoria, por conducto de Abundio, cuñado de Paz. Este recibe del "Instituto de Astrología", como contestación a su consulta en que dio las fechas de nacimiento de Lupe y $\mathrm{Paz}$, el siguiente consejo: "La persona de Aries puede hacer una perfecta unión con la de Leo". Al saberlo, Lupe exclama, eufórico, "iCongeniamos!" Paz, indiferente, califica a Abundio de "alcanfor" (alcahuete).

Pasan los años. Su hija se casa y, tal cual don Lupe se lo había predicho, a Paz le pesa la soledad. Entonces es cuando, con ilusiones juveniles y coquetería, le anuncia a don Lupe su decisión de entregarse en matrimonio. Pero como Felipe en la obra anterior, el ranchero la repudia, mas sin rencor ni venganza. Con toda su ingenuidad campesina, le participa que Sara, otta viuda del pueblo, está a punto de darle un hijo:

...me casaré el mes que entra pa'que no se junte el bautizo y la boda.

$\mathrm{Y}$ cuando Paz insiste, pidiéndole su jorongo en prendas de que regresará, Lupe accede dejárselo, pero únicamente como "un recuerdo de la luna y Venus que, como están tan lejos, no se juntan nunca". Soberbia, humildad, humillación. Así en sucesión sintética presenciamos los momentos culminantes que conducen a la derrota de la protagonista. Aunque su soberbia se ha transformado en un deseo de alcanzar la humildad (el jorongo), esto ha ocurrido demasiado tarde, por lo que ella tiene que pagar su egoísmo con creces: al par de verse abandonada de todos, será perseguida siempre por la humillación de aquel rechazo.

Respecto de esta obra, Carlos Solórzano, dramaturgo y crítico de teatro hispanoamericano, afirma que González Caballero ha logrado una obra "limpia, de excelente factura", sin mixtificaciones:

Los hechos no quieren decir más de lo que ellos mismos expresan y algunas escenas que conservan su simple sabor descriptivo se acercan a zonas más complejas, las de la magia popular que, absor- 
bida por las clases sociales superiores, le presta a la obra un especial encanto. ${ }^{9}$

La cuarta y última obra de este autor que sigue la temática del egoísmo femenino, es Nilo, mi bijo, que versa sobre una madre posesiva. Obra inédita y aún por estrenarse, es, sin duda, la más ambiciosa. Su acción abarca un período de 20 años, desde la adolescencia hasta la muerte de Nilo - dominado implacablemente por una madre soltera. E1 que no hubiera marido que interviniera en la crianza del hijo, explica su excesivo celo por dominarlo. Peto en donde yerra, sin perdón, es en imponerle una profesión que le repugna. Nilo es hermoso y ella se obstina en hacerlo médico para acabar de lucirlo del todo. Ya fracasado en la Universidad, el joven se pone a vender seguros, de casa en casa. Aparte de la influencia aplastante de la madre en su personalidad, Nilo se acompleja más al saber que vino al mundo a frustrar el gran amor de su madre, pues casi en vísperas de casarse, ella fue atacada por un loco que, tras ser golpeado e invalidado por los pueblerinos, tomó su propia vida colgándose de una cuerda. Esta es la imagen del padre que evoca reminiscencias de Ibsen, por un lado, y de Usigli (Otra primavera), por otro, a causa de la obsesión de la locura que puede manifestarse en el hijo posteriormente.

El acto final encierra la más grande miseria de madre e hijo, éste enfermo y envejecido a los 42 años. Anda vendiendo botellas de miel en las calles, cuando el encuentro de su antiguo amigo lo inspira a redimirse. Contrapone su voluntad a la de su madre por primera vez. Esto, a la anciana le produce un ataque; el hijo, exaltado con sus nuevos proyectos, ni siquiera acude a socorrerla. Sin embargo, al verla muerta, se culpa, se enloquece y se mata colgándose de una cuetda. Y el dramaturgo deja decidir al lector si la demencia de Nilo le sobreviene por herencia o por la crisis que sufre al verse desvalido en el mundo. En la protección nociva de la madre, tenemos un caso de la coexistencia del bien y el mal. Resulta, al fin y al cabo, tan absurdo como el caso extravagante planteado por Strindberg en El viaje de Pfedro el Afortunado, en que el héroe es recluido por su padre en un campanario, a fin de aislarlo de la maldad de los hombres. Pero la maldad de las mujeres puede ser más destructiva, según demuestra González Caballero al confirmar la futilidad de procurar alejar a los hijos de lo que es - quiérase o no- la Vida.

Al contar así los hechos escuetos de las obras, uno corre el péligro

9 Carlos Solórzano, "El medio pelo un sainete...", Siempre, abril 14, 1965, p. 18. 
de hacerlas parecer melodramáticas. Ello sería una injusticia en el caso del presente autor, quien prepara minuciosamente todos los antecedentes de un suceso con perspicacia sicológica para que, lejos de acontecer sin motivación, ocurra como consecuencia lógica de la acción. Lo que indiscutiblemente puede concluirse de todo lo anterior, es que Antonio González Caballero ha perseguido una temática adversa a la mujer, retratándola con los defectos aquí señalados — prejuicios sociales, soberbia, calumnia, envidia, celos y egoísmo-10 en cuatro estados distintos: la solterona (Señoritas a disgzisto), la joven madre casada (Una pura.. y dos con sal), la madre viuda (El medio pelo) y la madre soltera (Nilo, mi bijo). En las referidas obras, no se percata sino una mujer que merece calificarse como "buena": Sara, la que va a tener el hijo del ranchero, en El medio pidlo. Y aquel amor, ilícito y reprochable desde un punto de vista moral, se premia; no se castiga. Don Lupe se casará con ella, no porque se lo exige, sino porque la quiere. Con todo, es muy significativo que Sara nunca aparece en escena. Unicamente se refiere a ella, por lo que constituye una nebulosa figura invocada a fin de realzar, por contraste, el egoísmo de doña Paz, siendo a la vez el instrumento de su castigo.

Como última observación conviene aclarar que las situaciones denunciadas por este autor mexicano no son exclusivas de su país natal. Son consecuencia, en gran parte, de actitudes sociales y costumbres heredadas de la fusión de lo europeo y lo indígena, mismas que caracterizan a toda Hispanoamérica. En cuanto a la sustancia humana y los lunares que afean el carácter femenino, éstos tienen inevitablemente perfiles universales. Incluso, cabe preguntarse si González Caballero se dedica conscientemente a nutrir la ya abundante literatura misógina universal, o si sólo ha señalado al sexo débil, en toda su ruindad, como símbolo de la fragilidad humana.

ALyCE DE KUEHNE

University of California,

Santa Bärbara.

10 Es significativo que este autor janzás inculpa a la mujer ni de infidelidad ni de adulterio, 